\title{
Particle swarm optimisation (PSO) algorithm with reduced numberof switches in multilevel inverter (MLI)
}

\author{
Mohammed Rasheed, Rosli Omar, Marizan Sulaiman, Wahidah Abd Halim \\ Faculty of Electrical Engineering, Universiti Teknikal Malaysia Melaka, Malaysia
}

\begin{tabular}{l}
\hline \hline Article Info \\
\hline Article history: \\
Received Dec 12, 2018 \\
Revised Feb 13, 2019 \\
Accepted Feb 27, 2019 \\
\hline
\end{tabular}

\section{Keywords:}

Harmonics

Multilevel inverters

Newton raphson (NR)

Particle swarm optimization (PSO)

\begin{abstract}
In this work, a three-phase of multilevel inverter (MLI) with reduced number of switches components based on Newton Raphson (NR) and Particle Swarm Optimization (PSO) techniques were presented. The Selective Harmonic Elimination Pulse-Width Modulation (SHE-PWM) is a powerful technique for harmonic minimization in multilevel inverter within allowable limits. NR and PSO techniques were used to determine the switching angles by solving the non-linear equation's analysis of the output voltage waveform of the modified CHB-MLI in order to control the fundamental component. A comparison has been made between NR and PSO techniques related to optimization in order minimize harmonic distortion. The main aims of this paper cover design, modeling, construction the modified topology of the CHB-MLI for a three phase five levels inverter. The controllers based on NR and PSO were applied to the modified multilevel inverter. The inverter offers much less THD using PSO scheme compared with the NR scheme. The performance of the proposed controllers based on NR and PSO techniques done by using MATLAB/Simulink of results are compared.
\end{abstract}

Copyright (C) 2019 Institute of Advanced Engineering and Science. All rights reserved.

\section{Corresponding Author:}

Mohammed Rasheed,

Faculty of Electrical Engineering,

Universiti Teknikal Malaysia Melaka (CRIM-UTeM),

Industrial Power, 76100, Hang Tuah Jaya, Durian Tunggal, Melaka, Malaysia.

Email: rasheed@utem.edu.my

\section{INTRODUCTION}

One of the important features for CHB-MLI is the ability for this type to get a high AC voltage based on cascaded DC source [1], [2]. A single power semi-conductor cannot be connected to the medium voltage grids. Hence, this multilevel converter has emerged as a solution to this. Also, several semiconductor devices can be connected in series or parallel to meet this voltage or power requirement. In order to lower harmonic content to improve the output waveform for voltage inverter, reduce the size of the filter utilized and the level of electromagnetic interference (EMI). Multilevel inverter (MLI) are being preferred in high power medium voltage applications due to reduced voltage stresses on the devices. The MLI concept is used to reduce the THD in the voltage output waveform without decreasing the inverter output power. It has several advantages such as their switching can be staggered, which reduces the switching frequency and thus the switching losses, reduction of EMI and interfacing renewable energy sources such as PV to the electric power grid. Numerous topologies to realize this connectivity which can be generally divided into three major categories, namely, diode clamped MLI, flying capacitor MLI and separated dc sources cascaded H-bridge CHB-MLI. Type of MLI which using a single DC source rather than multiple sources is the diode-clamped MLI. While, FC type is designed by series connection of capacitor clamped switching cells. CHB switches are connected in parallel and series in order to provide high power demand and high-power quality [3]-[9], [10]. For improving the quality of the output voltage inverter for two types of MLI, as symmetrical and asymmetrical, both types are very effective and efficient for multilevel inverter utilize reduced number of 
switching devices with Hybrid topologies for the conventional and non-conventional multilevel inverter topologies to create a specified number of output voltage levels in operating in higher voltage levels [11], [12]. Reduced number of switches with installation area and cost and has simplicity of control system, with a high number of steps associated using a new topology of cascaded multilevel inverter (CHB-MLI) [10], [13]-[16]. A current source inverter (CSI) apply a new topology for multilevel with reduced number of switches to generate desired output current for multilevel based on sinusoidal pulse width modulation (SPWM) method. This topology employs $(n+7) / 2$ switches and $(n-1) / 2$ current-sharing inductors for an $n-$ level CSI [17]. For 5-level single-phase inverter has been developed by field-programmable gate array (FPGA). The digital control technique is generated based on multi carrier PWM in Altera DE2 board, which has many features that allow design application of the system device have been implementation Simulation and experiment results in [18]. A seven-level inverter has been simulated via implementation of PWM techniques to reduce total harmonic distortion (THD). Therefore, with decrees number of gate driver in the circuit, there will be an increase for high voltage inverter. The circuitry consists of smaller (CHB-MLI) blocks connected in series to implementation its characteristic output waveform [15], [19], [20].

In this paper a three phase SHE modulation of modified CHB-MLIs for five levels become an increasingly popular technology multilevel inverters due to their speed and flexibility. Most of the researchers applied PSO technique in a single phase of a conventional CHB-MLIs. The NR and PSO techniques are used to calculate switching angles with the capability to eliminate harmonics of the output CHB-MLIs.

\section{THE MODIFIED OF A CHB-MLIS FIVE-LEVEL CONFIGURATION}

The output voltage's of switching functions determine its harmonic components; thus, to some degree, reduction of harmonics is limited. Figure 1 shows the proposed single-phase five-level-inverter topology. As a solution, this work presents of switching pattern a five-level PWM inverter with output voltages zero, $+1 / 2 \mathrm{Vdc}, \mathrm{Vdc},-1 / 2 \mathrm{Vdc}$, and $-\mathrm{Vdc}$ as shown in Figure 2 based on Table 1. Increased number of output levels reduces harmonic content. It adopts a full-bridge configuration, with an auxiliary circuit comprising four diodes and a switch and generates half-level of dc bus voltage.

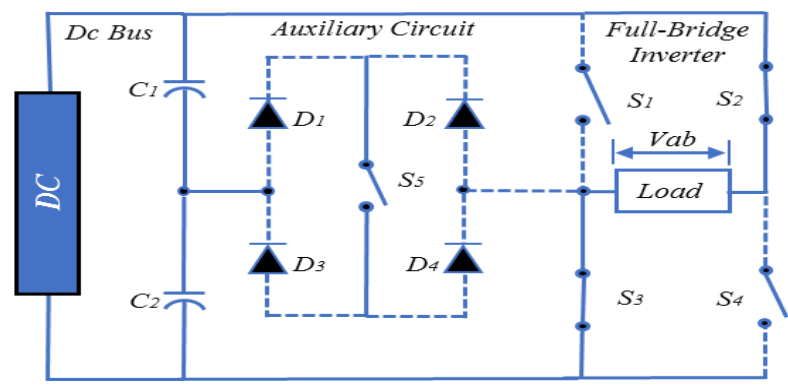

Figure 1. Proposal modified of a CHB-MLI, single-phase five-level topology
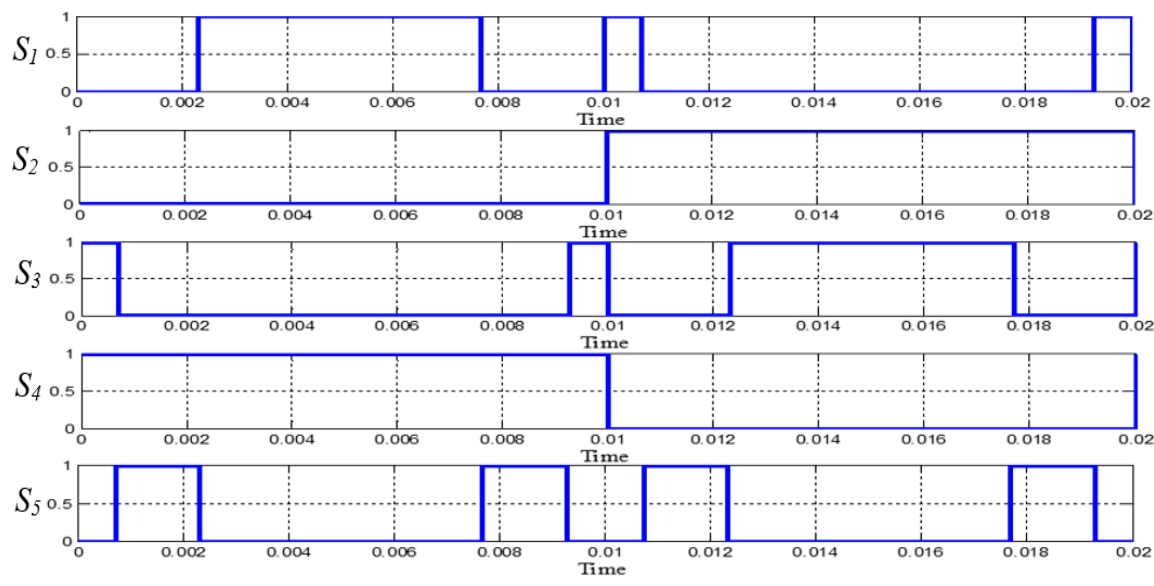

Figure 2. Switching pattern for 5-level modified of a CHB-MLI 


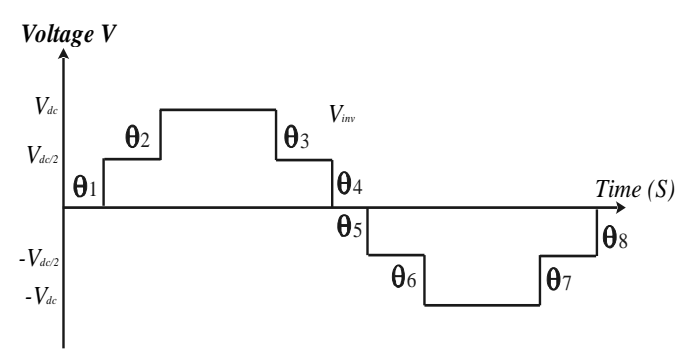

Table 1. Output voltage for five level to the switches'

\begin{tabular}{ccccccc}
\multicolumn{7}{c}{ on=1-off=0 condition } \\
\hline State & S1 & S2 & S3 & S4 & S5 & Vo \\
\hline A & 1 & 0 & 0 & 1 & 0 & Vdc \\
B & 0 & 0 & 0 & 1 & 1 & Vdc/2 \\
C & 0 & 0 & 1 & 1 & 0 & 0 \\
D & 1 & 1 & 0 & 0 & 0 & $0^{*}$ \\
E & 0 & 1 & 0 & 0 & 1 & $-\mathrm{Vdc} / 2$ \\
F & 0 & 1 & 1 & 0 & 0 & $-\mathrm{Vdc}$ \\
\hline
\end{tabular}

Figure 3. Vab at low switching frequency CHB-

MLIs, for 5-levels

\section{ANALYSES OF THE PROPOSED TOPOLOGIES OF A MODIFIED CHB-MLIS FOR FIVE LEVELS}

Fourier series for Output Voltage of Proposed of a Modified CHB-MLIs for Five Level The equations for 5-levels based on the Fourier series are described below [21]:

$$
f(t)=f_{\theta 1}(t)+f_{\theta 2}(t) \sum_{n=1,2,5}^{\infty} \frac{2 V d c}{n \pi}\left(V_{d c 1} \cos \left(n \alpha_{1}\right)+V_{d c 2} \cos \left(n \alpha_{2}\right)\right) \sin (n w t)
$$

where:

$V d c$ : Voltage of each voltage source that was in unity

$\theta i$ : The switching angles

From (2-1), four equations were resulted in eliminating the 5th harmonic.

$$
\begin{aligned}
& V_{A N}=V_{d c 1} \\
& b_{n}=\frac{2 V_{d c}}{\pi}\left\{\cos \left(n \alpha_{1}\right)+\cos \left(n \alpha_{2}\right)\right\} n=1,3,2
\end{aligned}
$$

As shown in (2) has s variables $\left(\theta_{1}, \theta_{2}\right)$, where $0<\theta_{1}<\theta_{2}<\pi / 2$, and a solution set is obtained by assigning a specific value to the fundamental component, Vf, and equating s-1 harmonics to zero as given below:

$$
V_{1} \cos \left(\theta_{1}\right)+V_{2} \cos \left(\theta_{2}\right) 6 m \quad V_{1} \cos \left(5 \theta_{1}\right)+V_{2} \cos \left(5 \theta_{2}\right)=0
$$

where $\mathrm{m}=\mathrm{Vf} /(2 \mathrm{Vdc} / \pi)$, and it is related to the modulation index $\mathrm{mi}$ by $\mathrm{mi}=\mathrm{m} / \mathrm{s}$, where $0<\mathrm{mi}<1$. An objective function is then needed for the optimisation procedure selected as a measure of effectiveness of eliminating selected order of harmonics while maintaining the fundamental component at a pre-specified value. Therefore, this objective function is defined as:

$$
\mathrm{F}\left(\theta_{1}, \theta_{2}, \ldots, \theta_{s}\right)=\left[\sum_{\mathrm{n}=1}^{\mathrm{s}} \mathrm{V}_{1} \cos \left(\theta_{\mathrm{n}}\right)-\mathrm{m}\right]^{2}+\left[\sum_{\mathrm{n}=1}^{\mathrm{s}} \mathrm{V}_{2} \cos \left(3 \theta_{\mathrm{n}}\right)\right]^{2}+\cdot\left[\sum_{\mathrm{n}=1}^{\mathrm{s}} \mathrm{V}_{\mathrm{s}} \cos (2 s-1) \theta_{\mathrm{s}}\right]^{2}
$$

The optimal switching angles are obtained by minimising Eq. (4) subject to the constraint $0<\theta_{1}<\theta_{2}<\pi / 2$, and consequently the required harmonic profile is achieved. The main challenge is the non-linearity of the transcendental set of (3), as most iterative techniques can be used with five levels of the modified CHB-MLIs as shown in Figure 4 and each step is explained below:

\subsection{NR Technique}

The values of the conducting angles $\theta_{1}, \theta_{2}$, can be chosen by solving the transcendental equations using a modulation index formula (5) to obtain the suitable

$$
M=\frac{\pi \mathrm{V} f}{2 V_{d c}}(0 \leq M \leq 1)
$$

Where, modulation index values, $\mathrm{m}_{\mathrm{i}}$. Other angles which are $\theta_{3}$ until $\theta_{8}$ can be obtained by referring the output waveform of 5-levels of a modified CHB-MLIs theory in Figure 3. The procedure of detecting attributes and configuration of a system is called optimisation. For only $5^{\text {th }}$ harmonics can be eliminated chosen to be removed. Thus, the switching angle can be found by solving transcendental equations by using NR technique. In order to generate $S_{1}, S_{2}, S_{3}, S_{8}$, for 5-levels inverter, the switching pattern as shown in 
Figure 3 are turned on and off in the right sequence in order to produce 5-level output voltage waveform of a modified CHB-MLIs. These switching angles are then examined for their corresponding THD given by:

$$
T H D_{V}=\frac{\sqrt{\sum_{n=1}^{\infty} V_{n}^{2}}}{V_{1}}
$$

The effect of optimised angles for five-levels are $\alpha_{1}$, and $\alpha_{2}$, on the THD and the modulation index is shown in Figure 3. By using MATLAB coding for number of iterations, it can be easily concluded that the modulation index equal 0.949. However, the THD value of five-levels equal to $16.19 \%$.

\subsection{Particle PSO Technique}

Particle swarm optimisation is a search algorithm which optimizes a given problem by iteratively choosing the possible best solution with regards to the given constraints [22]-[25]. The following are the steps required to solve the PSO based SHE algorithm for solving the non-linear transcendental equations and obtain the optimal switching angles. The number of iteration algorithm is solved using MATLAB coding to get better angles and harmonic. From number of iteration PSO algorithm.

Step 1 Initialise the system parameters such as position vector $\mathrm{Xi}$, velocity vector $\mathrm{Vi}$, personal best particle vector $\mathrm{Pi}$, global best vector $\mathrm{Pg}$, and particle inertia weight $\mathrm{C} 0$. Assign the values of generations as 100 , population size as 40 , cognitive parameter $\mathrm{C} 1$ as 0.5 and social parameter $\mathrm{C} 2$ as 1.25 .

Step 2 Check for the conditions $0<(\mathrm{C} 1+\mathrm{C} 2)<2$ and $(\mathrm{C} 1+\mathrm{C} 2) / 2<\mathrm{C} 0<1$, if the two conditions are satisfied then the system will be guaranteed to converge to a stable equilibrium point. If false, go to Step 1.

Step 3 Update the Velocity, Vi $(t+1)$.

$$
\operatorname{Vij}(\mathrm{t}+1)=\mathrm{Vi}(\mathrm{t})+\gamma_{1 i}\left(\mathrm{P}_{i}-\mathrm{x}_{i}(t)\right)+\gamma_{2 i}\left(\mathrm{G}_{i}-\mathrm{x}_{i}(t)\right)
$$

Step 4 Update the Position, Xi $(t+1)$.

$$
\mathrm{Xij}(\mathrm{t}+1)=\mathrm{Xij}(\mathrm{t})+\mathrm{Vij}(\mathrm{t}+1)
$$

where $i$ is the particle index, $\mathrm{j}$ is the index of parameter of concern to be optimised, $\mathrm{x}$ is the position of the ith particle and jth parameter, $\mathrm{k}$ is the discrete time index, $\mathrm{v}$ is the velocity of the ith particle and jth parameter, $\mathrm{P}$ is the best position found by the ith particle and jth parameter (personal best), $\mathrm{G}$ is the best position found by swarm (global best), $\mathrm{c}$ is a random uniform number between [0,1] applied to the ith particle, $u$ is the inertia function, $\mathrm{a}$ is the acceleration constants.

Step 5 Now, evaluate the particles using the Fitness Function

$$
T H D_{V}=\frac{\sqrt{\Sigma_{n=1}^{\infty} V_{n}^{2}}}{V_{1}}
$$

For harmonic elimination. Here the switching angles $\alpha_{1}$ and $\alpha_{2}$ are chosen in such a way that the selective harmonics $5^{\text {th }}$ eliminated.

$$
\begin{aligned}
& \mathrm{F}(1)=\left(\cos \left(\alpha_{1}\right)+\cos \left(\alpha_{2}\right)\right)-\mathrm{ma} \\
& \mathrm{F}(2)=\left(\cos \left(5 * \alpha_{1}\right)+\cos \left(5 * \alpha_{2}\right)\right)
\end{aligned}
$$

Step $60 \leq \alpha_{1} \leq \alpha_{2} \leq \pi / 2$.

Step $7 \mathrm{P}(\mathrm{xi})<\mathrm{P}(\mathrm{Pi})$, if not satisfied then $\mathrm{i}=\mathrm{i}+1$ go to Step 3. position.

Step 8 Update the local best position of the particle if it is better than the previous local best Thus, the local best position is replaced as $\mathrm{Pi}=\mathrm{Xi}$.

Step $9 \mathrm{Pg}=\min$ (P neighbour).

Step 10 Optimised switching angles are obtained. Terminate the problem.

The general flow chart of PSO of a modified CHB-MLIs for each step is explained in Figure 5: 


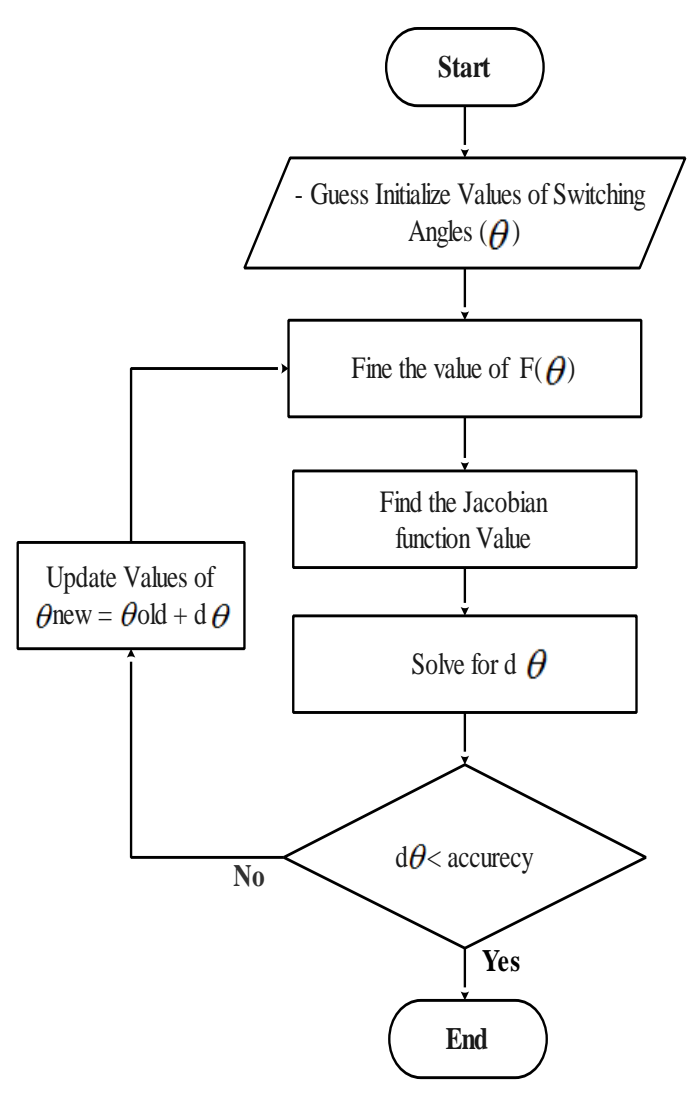

Figure 4. flow-chart of NR of the modified CHBMLIs

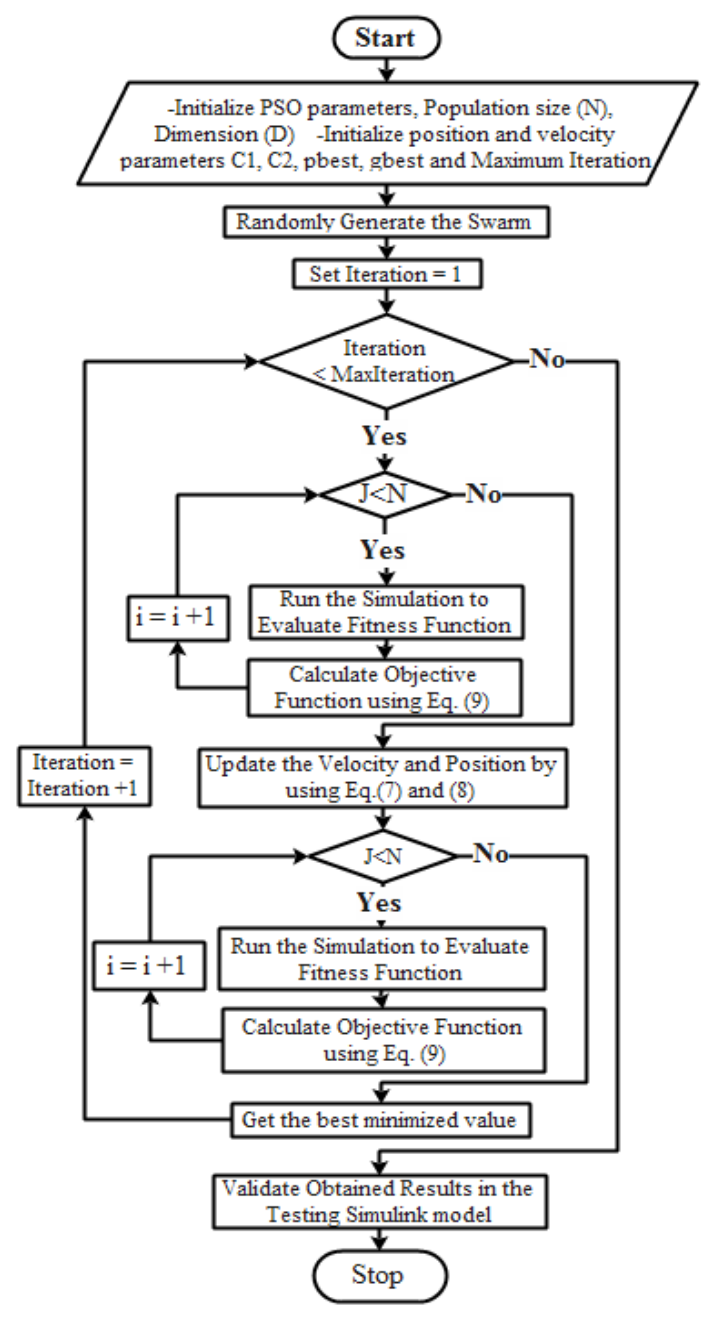

Figure 5. Flow chart of PSO of a modified CHBMLIs

\section{MODELLING OF THE PROPOSED MODIFIED CHB-MLIS}

MATLAB/SIMULINK software was used to model the proposed topologies of a modified CHBMLIs for five, levels. This was because the analysis and mathematical and engineering issues can be performed via MATLAB/SIMULINK. MATLAB has the feature of superior programming and graphics ability. Meanwhile, SIMULINK is used to model, analyse, and catalyze effective system block diagram, which is fully integrated with MATLAB, simple and smart to be learnt as well as flexible. Besides, it has an overall library of blocks that can be used to simulate systems of linear, nonlinear or discrete elements.

Figure 6 shows the circuit diagram of the proposed of a three-phase modified CHB-MLIs for fivelevels. The configuration of this model consists of 12 switches of the conventional inverter in addition to a three-bi-directional switch. This work intend to develop a PSO based on SHE algorithms for obtaining the optimal firing angles for harmonics elimination and compare it with the conventional NR based SHE algorithms. The system operation was simulated at low switching frequency. In this simulation model, three DC sources are selected equal to $100 \mathrm{~V}$. Pulse generator block is used to conduct the switching pattern and results of pulse generating will control the inverter based on NR and PSO algorithms. A resistor, $100 \mathrm{k} \Omega$ will be used as a load to the proposed modified CHB-MLIs model. The output phase voltage of modified CHBMLIs is 300 volts with frequency $50 \mathrm{~Hz}$. The series connected DC bus capacitors $\mathrm{C} 1$ and $\mathrm{C} 2$ were $2500 \mathrm{e}-6$ $\mathrm{mF}$, which split the $\mathrm{DC}$ bus voltage for each cell: $\mathrm{VDC} / 2,0,-\mathrm{VDC} / 2$. The middle point $\mathrm{n}$ of the capacitors is defined as the neutral point. 


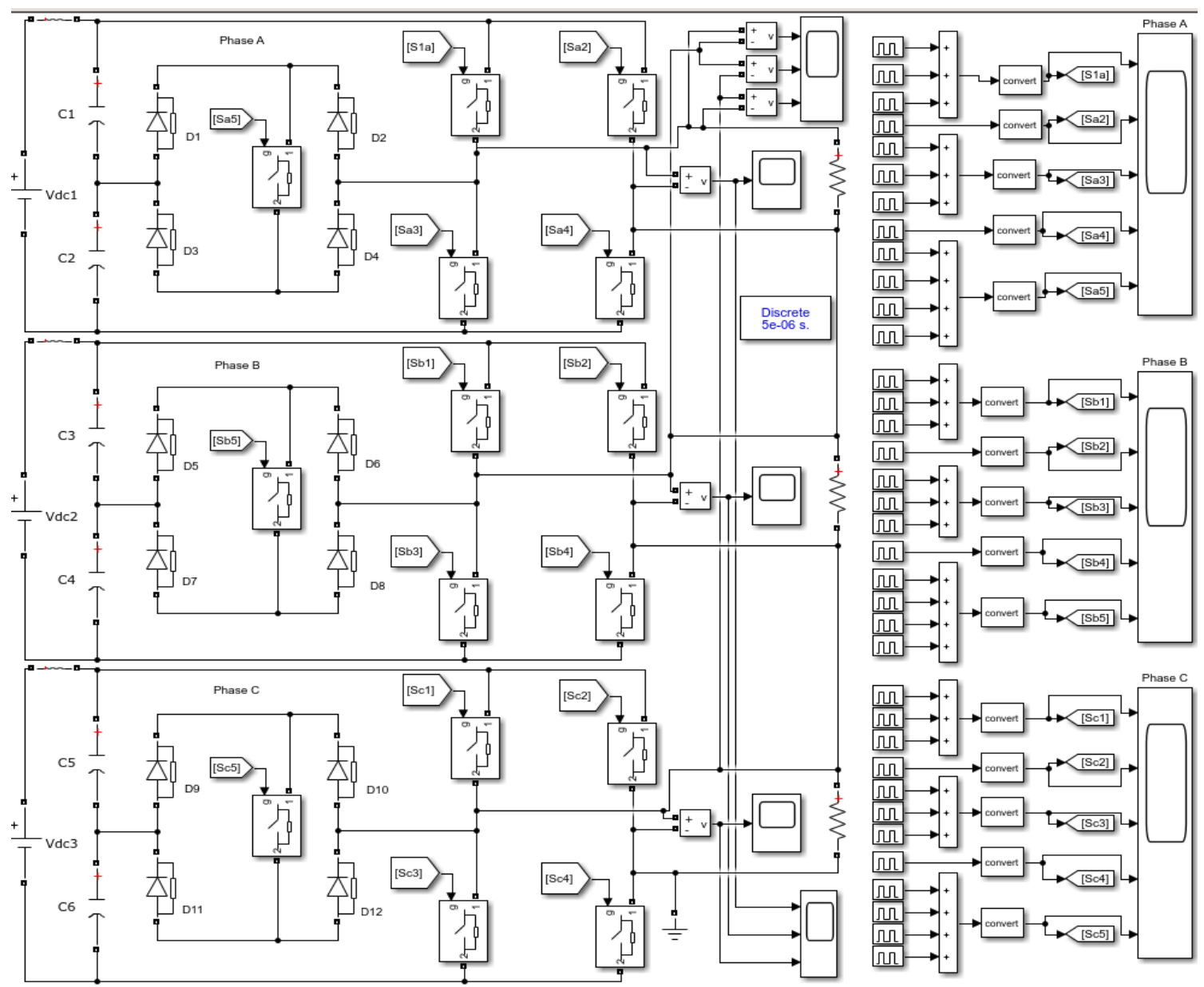

Figure 6. Simulations of a three phase of modified CHB-MLIs for five-levels model

\section{SIMULATION RESULTS FOR OPTIMIZATION OF THREE-PHASE WITH MI= 0.9 BASED ON NR AND PSO TECHNIQUES}

Simulations work has been carried out of a three phase of modified CHB-MLIs for value of switching frequency $2500 \mathrm{~Hz}$. The load used is a balanced three-phase star connected with $20 \mathrm{ohm}$, and $5 \mathrm{mH}$ per phase. The dc capacitor voltage Vdc $=150 \mathrm{~V}$. The first simulation of a three-phase modified CHB-MLIs operation was conducted using the NR technique. In this simulation operation, the duration of time was equal to $0.02 \mathrm{~s}$ for each cycle. The value of MI $=0.949$ was used and the switching angles were calculated and simulated, which were equal to $\theta_{1}=14.631$ and $\theta_{2}=41.343$ at the switches of a three-phase modified CHBMLIs of five levels.

In the case of simulation operation using PSO, the duration of time was equal to $0.02 \mathrm{~s}$ for each cycle. The value of MI=0.994 and the switching angles were calculated and simulated with values of $\theta_{1}=$ 13.404 and $\theta_{2}=41.908$ at the switches of a single-phase modified CHB-MLIs of five levels. The timing diagram of a three-phase modified CHB-MLIs of five levels was developed using the NR technique. There are four switches comprising switches S1, S2, S3, and S4 and bi-directional switch S5 as described in Figure 7, Figure 8 and Figure 9.

The simulation model of output voltage waveform is as shown in Figure 10 for the optimisation of phase voltage of a three-phase modified CHB-MLIs of five levels for phases A, B, and C, respectively. The optimisation of output voltage waveforms is based on the accurate calculation of switching angles obtained, which are $\theta I=14.6313$ and $\theta 2=41.3434$, with $\mathrm{MI}=0.949$. Using the NR technique, Figure 11 shows the harmonic spectrum of the optimisation of output voltage waveform of a three-phase modified CHB-MLIs of five levels with THD values equivalent to $16.3 \%$. 


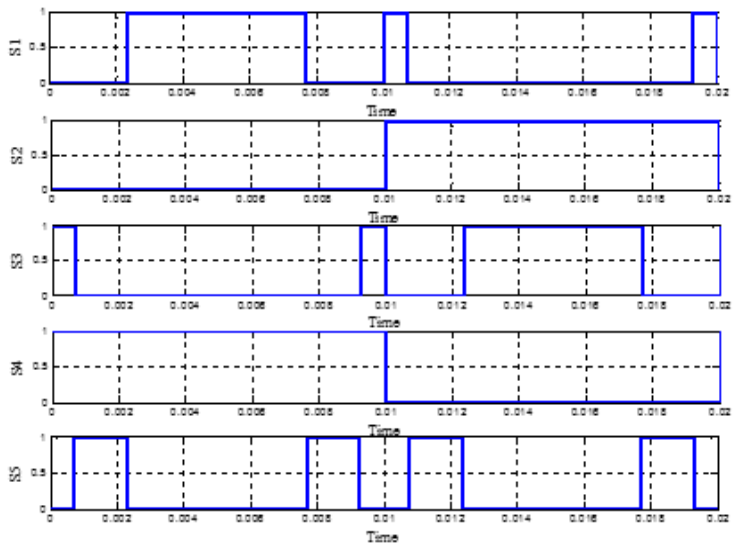

Figure 7. Timing diagram for $S_{1}, S_{2}, S_{3}, S_{4}$ and bi-directional $\mathrm{S}_{5}$ at phase A using NR technique

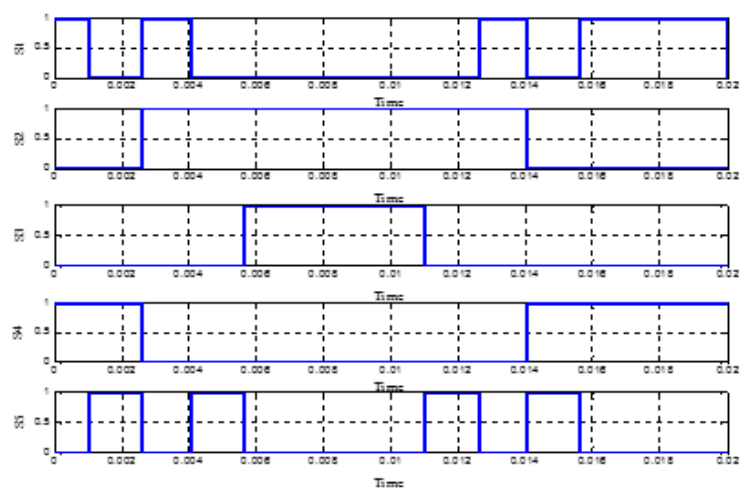

Figure 9. Timing diagram for $S_{1}, S_{2}, S_{3}, S_{4}$ and bi-directional $\mathrm{S}_{5}$ at Phase $\mathrm{C}$ using $\mathrm{NR}$ technique

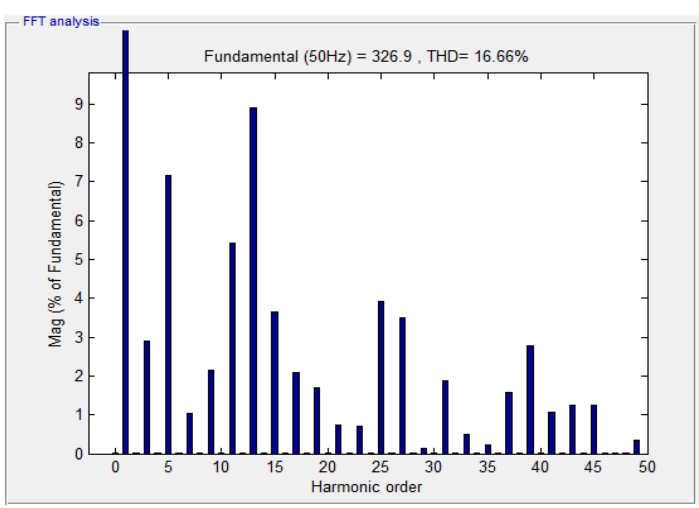

Figure 11. Harmonic spectrum for output phase voltage waveform using NR technique

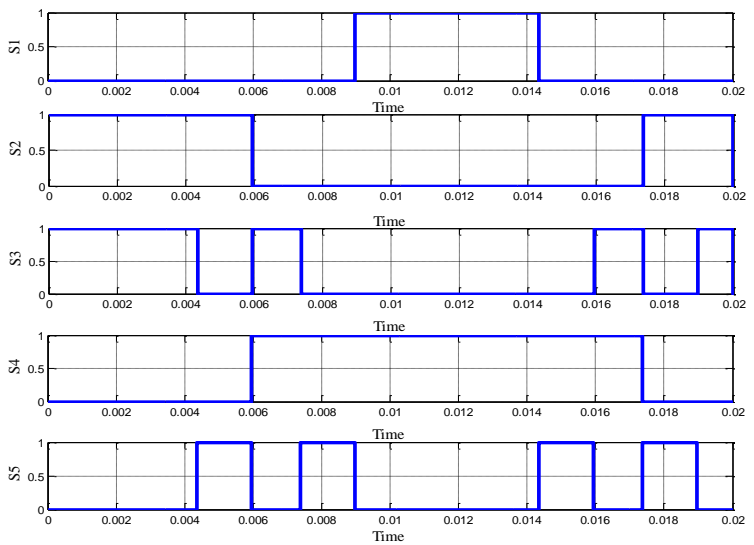

Figure 8. Timing diagram for S1, S2, S3, S4 and bi-directional S5 at phase B NR technique

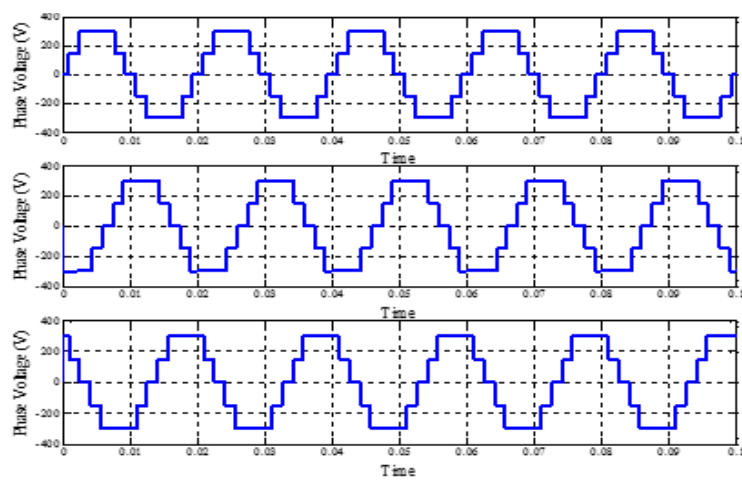

Figure 10. Three-phase five-level output phase voltage at phases $\mathrm{A}, \mathrm{B}$, and $\mathrm{C}$ with $\mathrm{MI}=0.949$ for $\theta_{1}=14.6313^{\circ}$ and $\theta_{2}=41.3434^{0}$ using NR technique

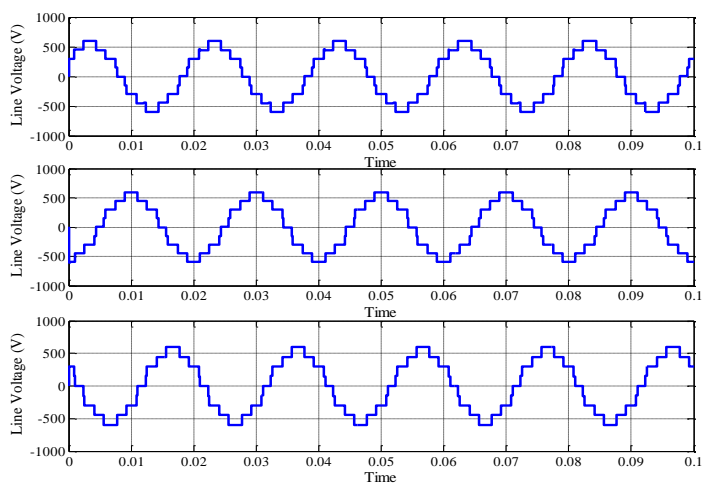

Figure 12. Three-phase five-level output line voltage at phases $\mathrm{A}, \mathrm{B}$, and $\mathrm{C}$ for $\theta_{1}=14.6313^{0}$ and $\theta_{2}=41.3434^{\circ}$ using NR technique

The line-to-line output voltage waveform of a three-phase modified CHB-MLIs of five levels using the NR technique can be illustrated in Figure 12. The output of the line-to-line voltage waveform will produce nine levels due to $\mathrm{V}$ line to line $=\mathrm{V}$ phase. The THD values for the line-to-line voltage are equivalent to $14.5 \%$ as shown in Figure 13. 
The second simulation was carried out for the proposed three-phase modified CHB-MLIs using the PSO technique. The timing diagram of a modified CHB-MLIs using the PSO technique can be illustrated in Figure 14, Figure 15, and Figure 16. There are differences in terms of pattern in switching the timing diagram among NR and PSO techniques due to the differences in the switching angle calculation for optimisation.

The calculation of switching angles obtained using the PSO technique is equal to $\theta_{1}=13.404326$ and $\theta_{2}=41.908579$ with $\mathrm{MI}=0.975$. The simulation model of output voltage waveform is as shown in Figure 17 Meanwhile, the optimisation of a three-phase modified CHB-MLIs of five levels using PSO with THD values equivalent to $15.34 \%$ is as shown in Figure 18.

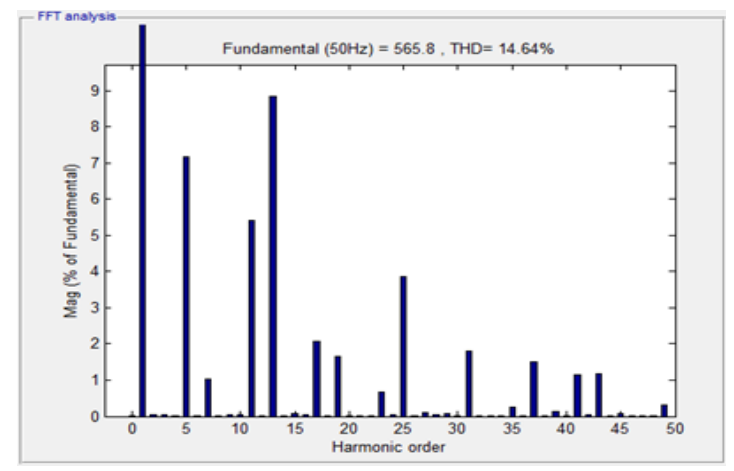

Figure 13. Harmonic spectrum for output line voltage waveform using NR technique

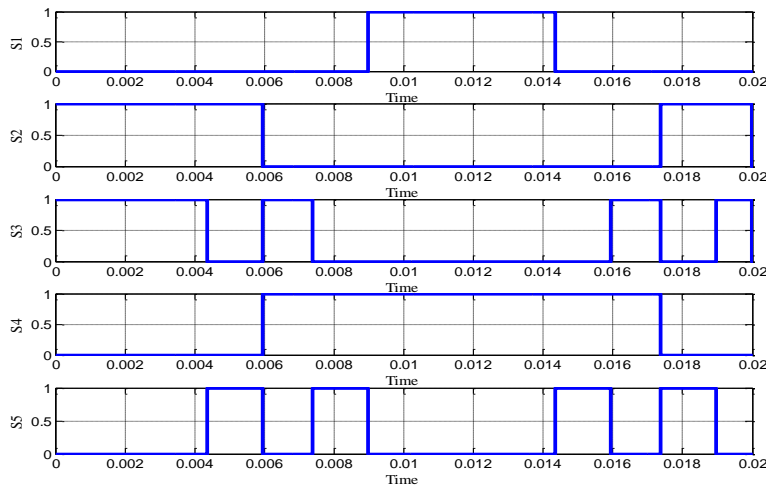

Figure 15. Timing diagram for $\mathrm{S}_{1}, \mathrm{~S}_{2}, \mathrm{~S}_{3}, \mathrm{~S}_{4}$, and $\mathrm{S}_{5}$ at phase $\mathrm{B}$ with $\mathrm{MI}=0.975$ using $\mathrm{PSO}$ technique

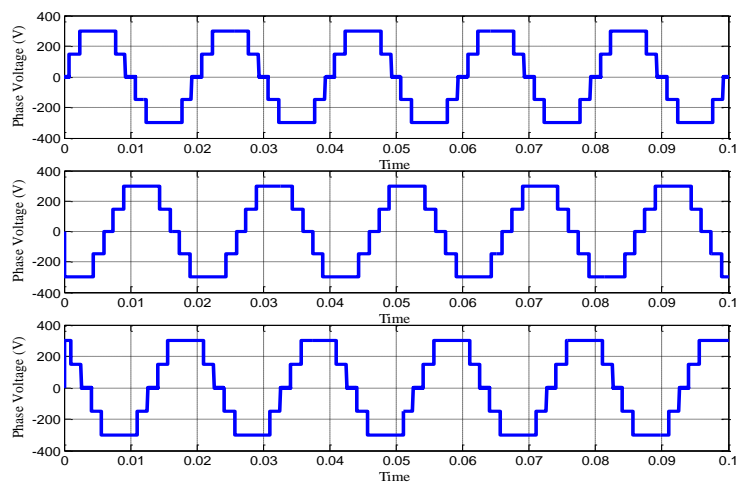

Figure 17. Simulation results for a 3-phase 5-level output phase voltage using PSO technique

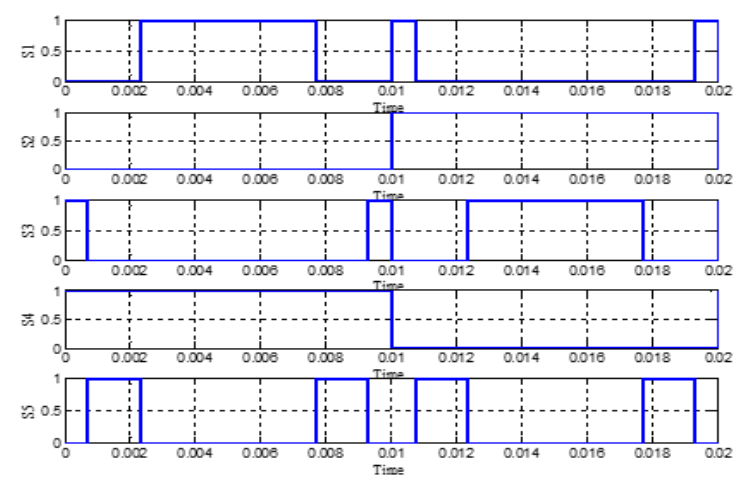

Figure 14. Timing diagram for $S_{1}, S_{2}, S_{3}, S_{4}$, and $S_{5}$ at phase A using PSO technique

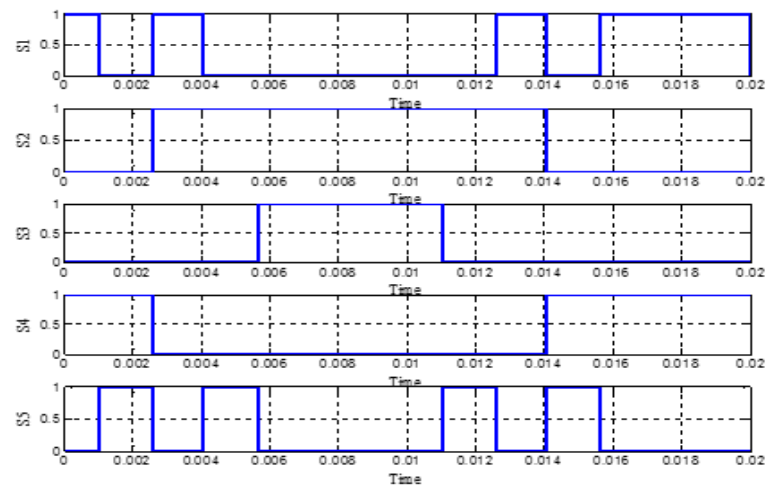

Figure 16. Timing diagram for S1, S2, S3, S4, and S5 at phase B using PSO technique

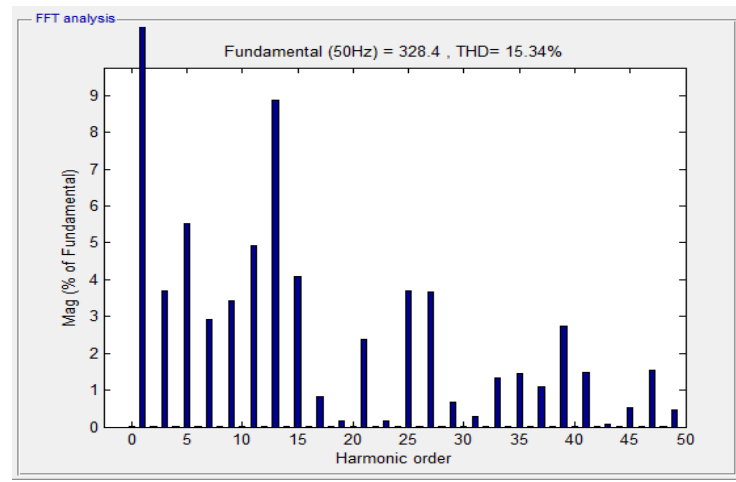

Figure 18. Harmonic spectrum for output phase voltage waveform using PSO technique 
In Figure 19 illustrates the line-to-line voltage output waveform of a three-phase modified CHBMLIs equal to 600v. The THD values for line-to-line voltage can be found in Figure 20 and its values are equal $12.81 \%$. The calculation of switching angles obtained is $\theta 1=13.404326$ and $\theta 2=41.908579$ with $\mathrm{MI}=0.975$. Figure 21 shows the MATLAB plotting output for switching angles and the THD values for voltage based on NR and PSO techniques. Based on of a three phase of modified CHB-MLs for simulation and experimental results showed that the higher level of inverter it will produce lower harmonics contents of the modified CHB-MLIs using the both techniques. However, PSO technique produce lower content of THD of the modified CHB-MLIs output voltage waveform compared to NR technique due to switching angles of the PSO technique is simple and efficient.
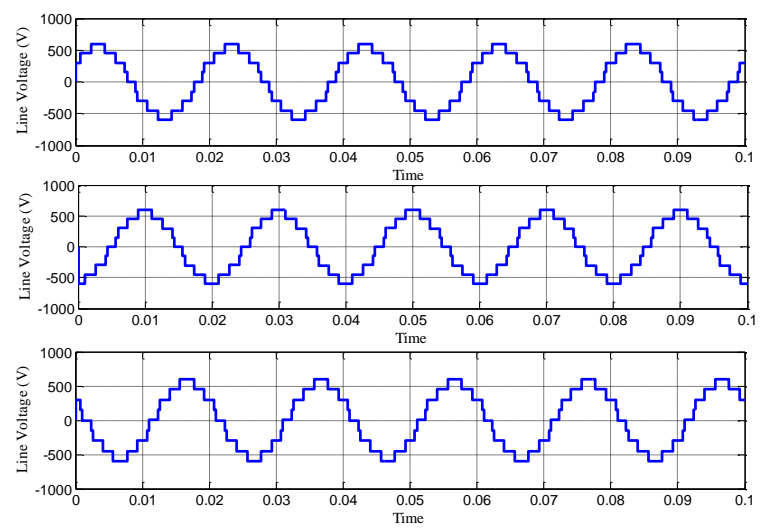

Figure 19. Simulation results for a three-phase fivelevel output line voltage at phases $\mathrm{A}, \mathrm{B}$, and $\mathrm{C}$ using

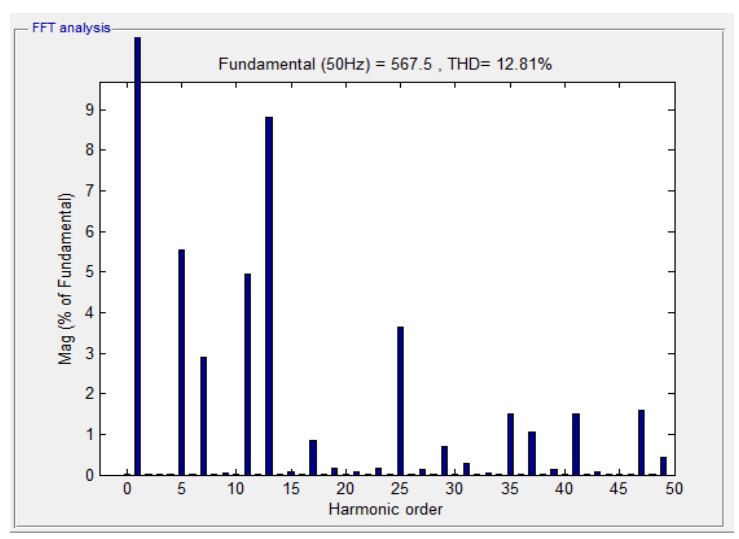

Figure 20. Harmonic spectrum for line-to-line voltage using PSO technique PSO technique

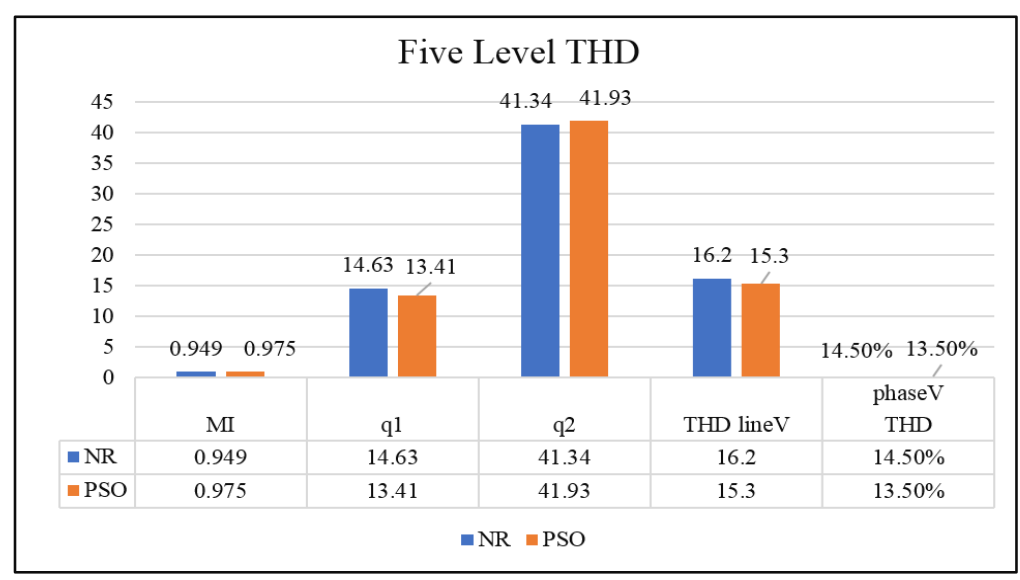

Figure 21. Overall values of MI, versus the switching angles and the values of THD for voltage of modified CHB-MLI of 5-levels based on NR and PSO

\section{CONCLUSION}

In order to run the simulation, a controller using NR and PSO techniques were applied to the modified CHB-MLIs for five levels. This work design and analysis, simulation of PSO algorithm with reduced number of switches in MLI were presented. Three phases of a modified CHB-MLIs were successfully developed. The low switching frequency control schemes operation can be implemented in the modified CHB-MLIs for five levels. The outcome of the results from simulation showed that the higher level of inverter it will produce lower harmonics contents of the modified CHB-MLIs using NR and PSO techniques. The, PSO technique produce lower content of THD of the modified CHB-MLIs output voltage waveform compared NR technique due to switching angles of the PSO technique is simple and efficient. 


\section{ACKNOWLEDGEMENTS}

This research is sponsored by the Fundamental Research Grant Scheme (FRGS) which the number is FRGS/1/2016/ TK04/FKE-CERIA/F00306. The authors wish to thanks to the Ministry of Education Malaysia for the funding to support this project and also to thanks to UTeM in providing the facilities and research environment. The authors would also to thank the Centre for Research and Innovation Management Universiti Teknikal Malaysia Melaka (CRIM-UTeM).

\section{REFERENCES}

[1] J. P. Baharu, "Harmonic Reduction of Cascaded H-Bridge Multilevel Inverter Based on Newton-Raphson," vol. 10, no. 3, pp. 6569-6580, 2015.

[2] M. Rasheed, R. Omar, A. Sabari, and M. Sulaiman, "Validation of a Three-Phase Cascaded Multilevel Inverter based on Newton Raphson ( N. R.)," vol. 9, no. May 2016, pp. 1-13.

[3] M. Jones and I. N. W. Satiawan, "A simple multi-level space vector modulation algorithm for five-phase open-end winding drives," Math. Comput. Simul., vol. 90, pp. 74-85, Apr. 2013.

[4] S. K. Mondal, B. K. Bose, L. Fellow, and V. Oleschuk, "Space Vector Pulse Width Modulation of Three-Level Inverter Extending Operation Into Overmodulation Region," IEEE Trans. POWER Electron., vol. 18, no. 2, pp. 604-611, 2003.

[5] R. N. A. Krismadinata, H. W. Ping, and J. Selvaraj, "Elimination of Harmonics in Photovoltaic Seven-level Inverter with Newton-raphson Optimization," Procedia Environ. Sci., vol. 17, pp. 519-528, 2013.

[6] U. B. S. D, "H ARMONIC O RIENTATION OF P ULSE W IDTH M ODULATION," POWER Eng. Electr. Eng., vol. 9, no. 1, pp. 29-34, 2011.

[7] A. Fri, R. El Bachtiri, and A. El Ghzizal, "A Comparative Study of Three Topologies of Three-phase (5L) Inverter for a PV System," Energy Procedia, vol. 42, pp. 436-445, 2013.

[8] O. Abdel-Rahim, H. Abu-Rub, and A. Kouzou, "Nine-to-Three Phase Direct Matrix Converter with Model Predictive Control for Wind Generation System,” Energy Procedia, vol. 42, pp. 173-182, 2013.

[9] B. Boost, V. Current, S. Inverter, Q. Lei, S. Member, and F. Z. Peng, "Space Vector Pulsewidth Amplitude Modulation for a," vol. 29, no. 1, pp. 266-274, 2014.

[10] M. A. and Z. H. Hajir Satih Abbas, Sohaimi Abu Bakar, "Experimental studies on corrugated steel-concrete composite slab," Građevinar, vol. 67, no. 3, pp. 225-233, 2015.

[11] E. Babaei, M. F. Kangarlu, and F. N. Mazgar, "Symmetric and asymmetric multilevel inverter topologies with reduced switching devices," Electr. Power Syst. Res., vol. 86, pp. 122-130, May 2012.

[12] R. a Ahmed and S. Mekhilef, "New multilevel inverter topology with minimum number of switches," TENCON 2010 - 2010 IEEE Reg. 10 Conf., pp. 1862-1867, Nov. 2010.

[13] S. H. H. Ebrahim Babaei, "New multilevel inverter topology with minimum number of switches," IEEE Reg. 10 Annu. Int. Conf. Proceedings/TENCON, vol. 50, no. 11, pp. 1862-1867, 2010.

[14] R. Omar, M. Rasheed, N. Mies, M. Sulaiman, W. A. B. D. Halim, and K. Krismadinata, "A NEW ALGORITHM WITH DIFFERENT MODULATION INDEX ( MI ) IN CASCADED H-BRIDGE MULTILEVEL INVERTERS ( CHB MLIS )," vol. 97, no. 3, pp. 856-866, 2019.

[15] R. Omar, M. Rasheed, Z. K. Low, and M. Sulaiman, "DESIGN AND DEVELOPMENT OF ACTIVE POWER FILTER FOR HARMONIC MINIMIZATION USING SYNCHRONOUS REFERENCE FRAME ( SRF )," vol. 14, no. 2, pp. 476-484, 2019.

[16] A. Z. Adnan, M. E. Yusoff, and H. Hashim, "Analysis on the Impact of Renewable Energy to Power System Fault Level," vol. 11, no. 2, pp. 652-657, 2018.

[17] S. H. Hosseini, M. F. Kangarlu, and A. K. Sadigh, "A New Topology for Multilevel Current Source Inverter with Reduced Number of Switches," Electr. Electron. Eng. 2009. ELECO 2009. Int. Conf. on. IEEE, pp. 273-277, 2009.

[18] W. A. Halim and N. A. Rahim, "FPGA-based pulse-width modulation control for single-phase multilevel inverter," 2011 IEEE 1st Conf. Clean Energy Technol. CET 2011, pp. 57-62, 2011.

[19] J. J. Nedumgatt, D. V. Kumar, A. Kirubakaran, and S. Umashankar, "A multilevel inverter with reduced number of switches," 2012 IEEE Students' Conf. Electr. Electron. Comput. Sci. Innov. Humanit. SCEECS 2012, vol. 1, 2012.

[20] K. M. Kotb, A. E. Hassan, and E. M. Rashad, "Implementation of Genetic Algorithm-Based SHE for a Cascaded Half-Bridge Multilevel Inverter Fed from PV Modules,” pp. 3-8, 2017.

[21] R. Vijayakumar, "Selective Harmonic Elimination PWM Method using Seven Level Inverters by Genetic Algorithm Optimization Technique," Int. J. Eng. Res. Technol., vol. 4, no. 2, pp. 812-818, 2015.

[22] A. K. Al-Othman and T. H. Abdelhamid, "Elimination of harmonics in multilevel inverters with non-equal dc sources using PSO,” Energy Convers. Manag., vol. 50, no. 3, pp. 756-764, 2009.

[23] S. Sudha Letha, T. Thakur, and J. Kumar, "Harmonic elimination of a photo-voltaic based cascaded H-bridge multilevel inverter using PSO (particle swarm optimization) for induction motor drive," Energy, vol. 107, pp. 335-346, 2016.

[24] V. K. Gupta and R. Mahanty, "Optimized switching scheme of cascaded H-bridge multilevel inverter using PSO," Int. J. Electr. Power Energy Syst., vol. 64, pp. 699-707, 2015.

[25] B. Alamri, A. Sallama, and M. Darwish, "Optimum SHE for Cascaded H-Bridge Multilevel Inverters Using : NRGA-PSO, Comparative Study,” pp. 1-10, 2015. 


\section{BIOGRAPHIES OF AUTHORS}

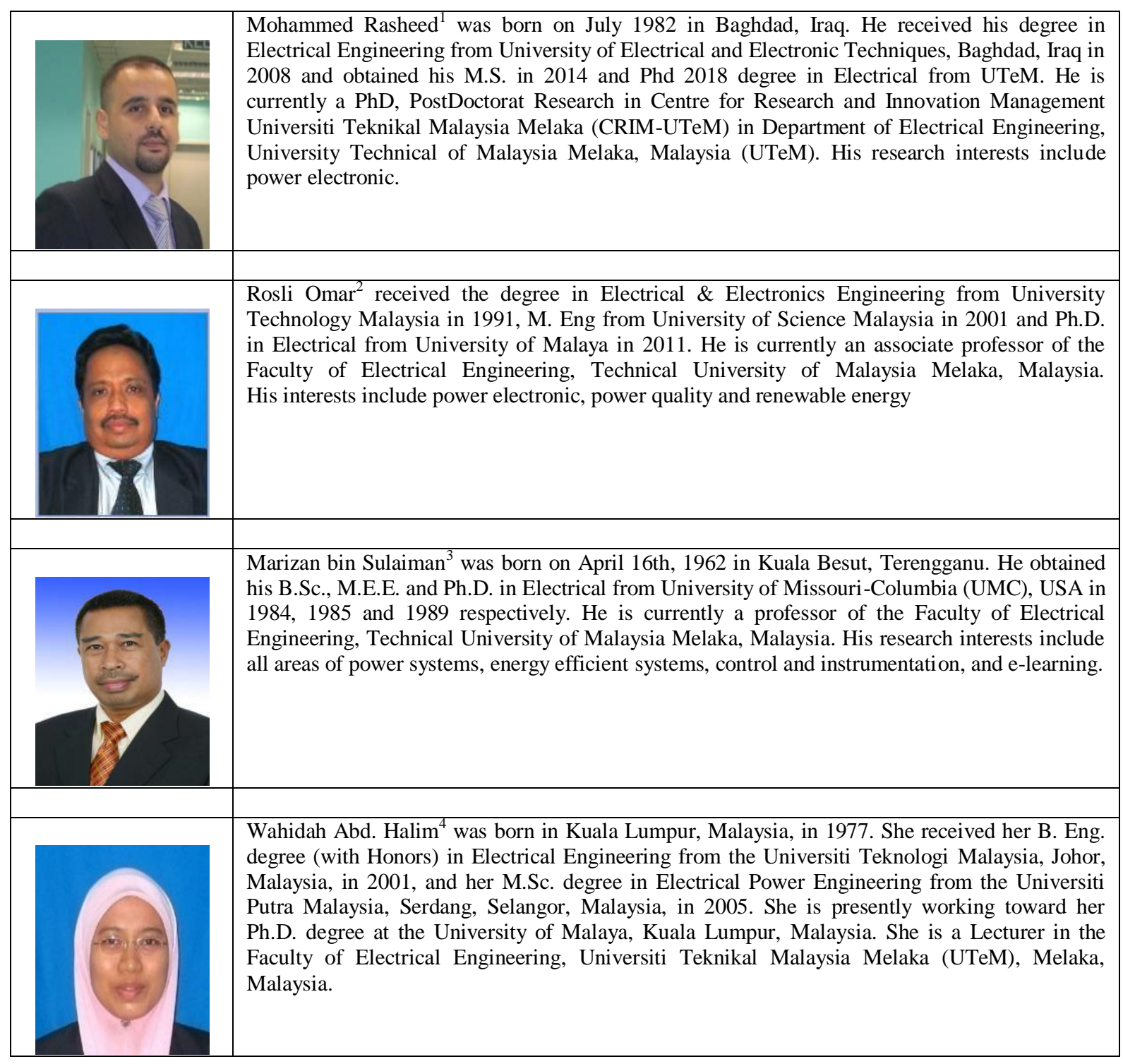

